\title{
Early life lung function and respiratory outcome in the first year of life
}

\author{
Nienke van Putte-Katier*, Anne C. van der Gugten*, Cuno S.P.M. Uiterwaal*,\#, \\ Brita M. de Jong*, Mattijs E. Numans ${ }^{\#}$, Jan L.L. Kimpen`, Theo J.M. Verheij ${ }^{\#}$ \\ and Cornelis K. van der Ent*, for the WHISTLER study group
}

ABSTRACT: Abnormal early life lung function is related to wheezing in childhood; however, data on the association with cough are not available. We determined the relationship between early life lung function and wheeze and cough during the first year of life, adjusted for other possible risk factors.

Infants were participants of the Wheezing Illnesses Study Leidsche Rijn (WHISTLER). Lung function measurements were performed before the age of 2 months. Information on pre- and perinatal factors, general characteristics and anthropometrics were assessed by questionnaires. Follow-up data on respiratory symptoms were assessed by daily questionnaires.

836 infants had valid lung function measurements and complete follow-up data for respiratory symptoms at 1 yr of age. Multivariable Poisson analysis showed that higher values of respiratory resistance $(R r s)$ and time constant $(\tau \mathrm{rs})$ were associated with an increased risk for wheeze and cough during the first year of life. Higher values of respiratory compliance (Crs) were associated with a decreased risk for wheeze and cough.

Rrs, Crs and $\tau$ rs measured shortly after birth were independently associated with wheeze and cough during the first year of life. As the strength of the relationships were different for wheeze and cough, they should be used as two separate entities.

KEYWORDS: Birth cohort, cough, infant, lung function, respiratory outcome, wheeze

W heezing illnesses in childhood are a major public health problem and several studies have suggested that the prevalence is increasing [1-4]. Although the aetiology of early childhood wheezing is not fully understood, the search for determinants is focused increasingly on exposures in utero and in early infancy, which may influence early lung development [5-9]. A few prospective cohort studies investigated pre-morbid lung function in association with subsequent respiratory disease and suggested that abnormal early life lung function is associated with subsequent wheezing in infancy and early childhood [10-15]. This suggests that abnormal early life lung function is a major risk factor for wheezing in early life that may persist through childhood and adolescence.

There are some issues that arise from these studies. Although it is clear that abnormal early life lung function is related to wheezing in early childhood, data on the association between early life lung function and subsequent cough are not available. Several studies investigated wheeze and cough in later childhood and suggested that these symptoms are different clinical entities with different aetiologies and may have different determinants [16-18]. Chronic or persistent cough has been suggested as an asthma phenotype [19] and it may be important to identify persistent coughers. Another issue arising from these studies is the use of retrospective questionnaires to estimate the relationship between early life lung function and respiratory symptoms. It is difficult to assess how accurate a retrospective questionnaire is in providing data on respiratory symptoms; in particular, recall bias by parents might interfere with accuracy. In addition, several studies have reported that parents often confuse wheeze with other respiratory sounds, which may lead to under- or overestimation of the true prevalence of wheeze [20-22]. The possible misclassification in subjectively reported symptoms could be improved by instructing parents on how to recognise the various respiratory sounds before filling in the daily questionnaires. This has been shown by our group to be an effective way to monitor airway symptoms consistently on a daily basis [23].

As part of the Wheezing Illnesses Study Leidsche Rijn (WHISTLER), the primary objective of the present study was to examine the relationship

\section{AFFILIATIONS}

*Dept of Pediatric Pulmonology, 'Dept of Pediatric Infectious Disease and

\# Julius Center for Health Sciences and Primary Care, University Medical Center Utrecht, Utrecht, The Netherlands

CORRESPONDENCE

N. van Putte-Katier Dept of Paediatric Pulmonology University Medical Centre Utrecht Internal Postal Code KH 01.419.0 PO Box 85090 3508 AB Utrecht The Netherlands E-mail: nkatier@yahoo.com

Received:

Nov 142010

Accepted after revision:

Dec 042011

First published online:

April 102012 
between early life lung function and the number of days with exclusive wheeze and exclusive cough as two separate entities during the first year of life, adjusted for several other possible risk factors for wheeze and cough. The secondary objective was to report associations between early life lung function and nonexclusive wheeze and cough.

\section{METHODS}

\section{Study population}

All neonates and infants in the current study are participants of WHISTLER, a prospective population-based birth cohort study on determinants (including early life lung function) and prediction of wheezing illnesses. Study design and rationale of WHISTLER have been described in detail elsewhere [24]. Briefly, healthy neonates and infants born in a newly developed residential area in the Netherlands (i.e. Leidsche Rijn), were invited by telephone to participate in this study before the age of 2 months before any respiratory illness was present. Exclusion criteria were gestational age $<36$ weeks, age $>2$ months, major congenital abnormalities and neonatal respiratory disease. The paediatric medical ethics committee of the University Medical Center Utrecht, Utrecht, the Netherlands, approved the study. Written informed consent was obtained from the parents.

\section{Lung function measurement}

Lung function was measured before the age of 2 months. Measurements were performed during natural sleep without the use of any sedation. Data collection was confined to consecutive periods of quiet sleep in which posture was stable and respiration was regular. Lung function was assessed from measurement of passive respiratory mechanics (resistance (Rrs), compliance $(\mathrm{Crs})$ and time constant $(\tau \mathrm{rs})$ of the respiratory system) using the single occlusion technique (SOT) [25, 26]. Airflow was measured using a heated Lilly-type pneumotachometer (series 8300, dead space $1.66 \mathrm{~mL}$, resistance $0.4 \mathrm{cmH}_{2} \mathrm{O}$ at $5 \mathrm{~L} \cdot \mathrm{min}^{-1}$; Hans Rudolph Inc., Kansas City, MO, USA) attached to a face mask (infant mask; Hans Rudolph Inc.). The mask was sealed to the infant's face using therapeutic silicone putty (Magic Putty; Oldelft Benelux BV, Delft, the Netherlands) to prevent air leaks and to minimise dead space. Pressure changes at the airway opening were measured with a pressure transducer (type 163PC01D75, Honeywell; Morristown, NJ, USA). Volume was obtained by electronic integration of the airflow signal. Flow, volume and pressure were digitised with a sampling rate of $200 \mathrm{~Hz}$ and interfaced to a computer for realtime display, storage and analysis. Before each measurement, calibration of flow and volume signals was performed using a 100-mL precision syringe (Viasys Health, Höchberg, Germany). The pressure transducer was calibrated over the expected range using a pressure transducer tester $\left(\right.$ VeriCal $^{\mathrm{TM}}$; Utah Medical Products Inc., Midvale, UT, USA). To be considered acceptable, each occlusion was required to meet the criteria of the American Thoracic Society/European Respiratory Society Task Force on Infant Lung Function [27]. At least three technically acceptable occlusions were used to calculate mean $C$ rs, $\operatorname{Rrs}$ and $\tau$ rs values. Lung function data were calculated offline using a custom-built software package (Luna 1.7, Utrecht, the Netherlands).

\section{Baseline characteristics and follow-up data}

A questionnaire completed in by one of the parents at the time of lung function measurement was used to gather information on gestational age, birthweight and birth length, older siblings and exposure to tobacco smoke (active and passive maternal smoking during pregnancy and passive smoking of the child after birth). Weight and length of the infant were measured at the visit. Data on parental demographics, social background and disease history were obtained from the linked database of the Utrecht Health Project (Leidsche Rijn Gezondheids Project), a dynamic population study in primary care conducted in a newly developed residential area in the Netherlands (i.e. Leidsche Rijn). By 2025, it is expected that 80,000-100,000 people of various ages social, cultural and economic backgrounds will have settled there. This study aims to generate data from all inhabitants on determinants of health and disease as described previously [24, 28].

1-yr follow-up for wheeze and cough after infant lung function measurement was achieved by a daily questionnaire completed by the parents in a logbook. Parents were carefully instructed at the time of lung function measurement by one of the investigators on how to recognise the various respiratory sounds. Daily complaints of wheeze and cough were measured using the questions: "Did your child wheeze today (whistling sound from the chest, not from the upper airways/throat)?" and "Did your child cough today?". Further questions were asked about anthropometrics and environmental factors, such as feeding patterns, passive smoking, daycare attendance, siblings and pets, during the first year of follow-up. New questionnaires and reinforcements to complete them were sent on a monthly basis to the parents. If parents still failed to return the questionnaire, they were contacted by telephone. Infants were considered lost to follow-up if $>3$ months of follow-up data were missing. To quantify respiratory symptoms, number of days with wheeze (with or without cough), cough (with or without wheeze), exclusive wheeze (without cough) and exclusive cough (without wheeze) were counted and analysed per year and per quarter.

\section{Definition of main determinants}

The self-reported information on parental asthma or bronchitis was based on the question "Have you had asthma or bronchitis during the past 12 months that has (ever) been diagnosed by a general practitioner or specialist?" The self-reported information on parental allergy was based on the question: Have you had allergy during the past 12 months that has (ever) been diagnosed by a general practitioner or specialist?" A positive history of allergy included allergy to pollen, house dust mite, pets, drugs or food. Based on the questionnaire of the Utrecht Health Project, parents were divided into three smoking categories (never, ex- and current smoker). Based on the WHISTLER questionnaire at the time of inclusion, three additional smoking variables were available (active and passive maternal smoking during pregnancy and passive smoking of the child after birth before inclusion in the study). Active maternal smoking during pregnancy was considered present if the mother smoked at least one cigarette per day and passive maternal smoking was considered present if the mother was exposed to tobacco smoke for $>2$ h per week. Passive smoking of the infant after birth and before inclusion in the study was defined as present if parents or caregivers smoked in the primary residency. Finally, data on smoke exposure of the infant during the first year of follow-up was available from the parental logs (positive if one of the 
parents or caregivers smoked in the primary residency). Socioeconomic status of the parents was based on educational level and defined as low (no formal education, lower secondary education or intermediate secondary education), middle (higher secondary education) or high (higher vocational or university education). The ethnic origin was classified as Caucasian versus non-Caucasian. Breastfeeding was defined as exclusive breastfeeding versus partial or no breastfeeding assessed on a monthly basis. As in this cohort few mothers continued breastfeeding beyond 6 months (table 1), we used exclusive breastfeeding during 6 months versus partial or no breastfeeding as potentially confounding variable in all the analyses. Daycare attendance was defined as ever attending daycare or a private home daycare versus never. Regarding birth season, infants were divided in two groups: birth in spring and summer compared with birth in autumn and winter.

\section{Statistical analysis}

The objective of this study was to investigate the relationship between early life lung function measurement and (exclusive) wheeze and (exclusive) cough during the first year of followup. To allow statistical analyses of incomplete data, missing values were replaced with the mean number of days with wheeze and cough of the other months as discussed previously [23]. Thus, missing values were replaced by values that were completely dependent on observations of the same person. As the main outcome of interest (number of days with symptoms) showed a right-sided distribution, we used Poisson regression for these data. We constructed univariable Poisson regression models to investigate the relationship between $R \mathrm{rs}, C_{\mathrm{rs}}$ and $\tau \mathrm{rs}$ and number of days with (exclusive) wheeze and (exclusive) cough in the first year of follow-up. Subsequently, multivariable Poisson regression models were constructed to investigate whether early life lung function was independently related to number of days with (exclusive) wheeze and (exclusive) cough. Adjustments were made for sex, gestational age, birthweight and length, siblings, birth season, maternal age, parental history of asthma or allergy, pre- and post-natal parental smoking, parental socioeconomic status, ethnicity, presence of pets during pregnancy, and breastfeeding and daycare attendance during the first year of follow-up. The multivariable Poisson regression models with exclusive wheeze and exclusive cough as outcome variables were not only adjusted for the listed covariates but also for exclusive cough and exclusive wheeze, respectively. In order to further examine the effect of early life lung function and respiratory symptoms in the first year of follow-up, the year was divided into four quarters and the number of days of symptoms was counted separately for each quarter. Both univariable and multivariable Poisson regression analyses were performed with the above-mentioned variables for each of the four quarters. Results are presented as incidence rate ratio (IRR) with their $95 \%$ confidence interval and p-values. Intervals not including 1 and p-values $\leqslant 0.05$ were considered statistically significant. Data analyses were performed using STATA version 10.0 (StataCorp, College Station, TX, USA).

\section{RESULTS}

\section{Subject characteristics}

Figure 1 shows an overview of recruitment and inclusion of infants in the ongoing WHISTLER study. Among the 1,483

\begin{tabular}{|c|c|}
\hline $\begin{array}{ll}\text { TABLE } 1 & \text { Characteristics of infant } \\
\text { function measurement a }\end{array}$ & $\begin{array}{l}\text { with successful lung } \\
\text { d 1-yr follow-up }\end{array}$ \\
\hline Subjects $n$ & 836 \\
\hline \multicolumn{2}{|l|}{ General characteristics } \\
\hline Female & 51.3 \\
\hline Gestational age weeks & $39.9 \pm 1.3(36.1-42.7)$ \\
\hline Age at time of measurement weeks & $4.6 \pm 1.3(1.4-8.7)$ \\
\hline Birthweight $g$ & $3529 \pm 503(1950-5540)$ \\
\hline Z-score birth weight-for-gestational age ${ }^{\#}$ & $0(-2.8-5.7)$ \\
\hline Birth length $\mathrm{cm}$ & $51.0 \pm 2.2(43.0-60.0)$ \\
\hline Z-score birth length-for-gestational age & $0(-4.1-3.7)$ \\
\hline Weight at measurement $\mathrm{g}$ & $4405 \pm 623(2650-7000)$ \\
\hline Length at measurement $\mathrm{cm}$ & $54.7 \pm 2.4(47.0-66.0)$ \\
\hline Head circumference $\mathrm{cm}$ & $37.4 \pm 1.4(33.0-43.3)$ \\
\hline Thoracic circumference $\mathrm{cm}$ & $37.4 \pm 2.5(26.0-49.0)$ \\
\hline \multicolumn{2}{|l|}{ Season of birth } \\
\hline Spring/summer & 48.6 \\
\hline Autumn/winter & 51.4 \\
\hline \multicolumn{2}{|l|}{ Lung function data } \\
\hline Crs $\mathrm{mL} \cdot \mathrm{kPa}^{-1}$ & $43.9 \pm 10.7(14.8-86.6)$ \\
\hline $\operatorname{Rrs~kPa} \cdot \mathrm{L}^{-1} \cdot \mathrm{s}^{-1}$ & $7.2 \pm 2.2(3.2-19.5)$ \\
\hline$\tau$ rs s & $0.316 \pm 0.120(0.062-0.978)$ \\
\hline \multicolumn{2}{|l|}{$\begin{array}{l}\text { Parental, prenatal and } \\
\text { postnatal factors }\end{array}$} \\
\hline Presence of pets during pregnancy & 40.1 \\
\hline Siblings & 49.8 \\
\hline Active maternal smoking during pregnancy & 5.4 \\
\hline Passive maternal smoking during pregnancy & 15.8 \\
\hline $\begin{array}{l}\text { Post-natal smoke exposure } \\
\text { infant before inclusion }\end{array}$ & 2.3 \\
\hline \multicolumn{2}{|l|}{ Smoke exposure during follow-up } \\
\hline 0-3 months & 14.0 \\
\hline $4-6$ months & 16.0 \\
\hline 7-9 months & 15.1 \\
\hline 10-12 months & 13.3 \\
\hline \multicolumn{2}{|l|}{ Exclusive breastfeeding } \\
\hline$\geqslant 3$ months & 30.4 \\
\hline$\geqslant 6$ months & 11.7 \\
\hline$\geqslant 9$ months & 4.0 \\
\hline 12 months & 1.4 \\
\hline \multicolumn{2}{|l|}{ Daycare attendance } \\
\hline 0-3 months & 46.2 \\
\hline $4-6$ months & 64.6 \\
\hline 7-9 months & 67.1 \\
\hline 10-12 months & 65.6 \\
\hline $\begin{array}{l}\text { Parental smoking status } \\
\text { current smoker } \mathrm{M} / \mathrm{F}\end{array}$ & $8.5 / 16.9$ \\
\hline $\begin{array}{l}\text { Parental history of asthma/ } \\
\text { bronchitis } M / F\end{array}$ & $8.1 / 6.4$ \\
\hline $\begin{array}{l}\text { Parental family history of } \\
\text { allergy } M / F\end{array}$ & $40.4 / 32.7$ \\
\hline $\begin{array}{l}\text { Parental socioeconomic } \\
\text { status high education M/F }\end{array}$ & $66.7 / 59.3$ \\
\hline Parental ethnicity Caucasian M/F & $81.4 / 84.1$ \\
\hline
\end{tabular}

Data presented as $\%$ and mean \pm SD (range), unless otherwise stated. \#: expressed as mean and range. Crs: compliance of the respiratory system; Rrs: resistance of the respiratory system; $\tau$ rs: time constant of the respiratory system; M: mother; F: father 


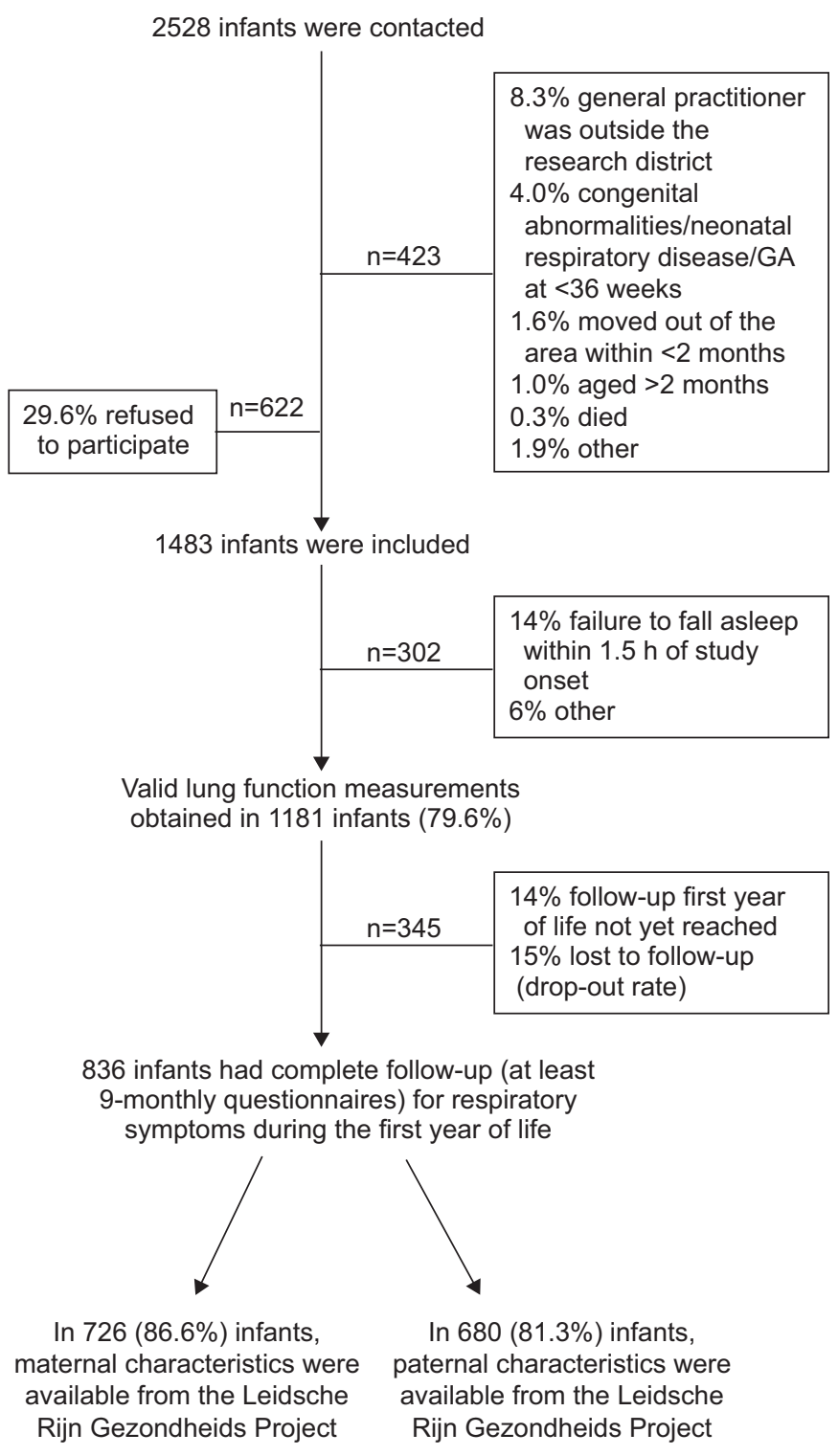

FIGURE 1. Overview of the inclusion of infants. GA: gestational age.

included infants, valid lung function measurements were obtained in 1,181 (79.6\%) infants. Failure to obtain technically acceptable measurements was mainly due to failure to fall asleep naturally within $1.5 \mathrm{~h}$ of study onset $(14 \%)$. Of the infants with successful lung function, complete follow-up data of respiratory symptoms during the first year of followup were available for 836 infants. Table 1 summarises the baseline characteristics and lung function data of these infants. There was no significant difference between the infants with complete follow-up compared with the infants lost to follow-up (data not shown). Maternal and paternal characteristics could be derived from the Utrecht Health Project for respectively $726(86.8 \%)$ and $680(81.3 \%)$ infants, respectively. Reported smoke exposure of the infant $(2.3 \%)$ between birth and before inclusion in the study at $<2$ months of age was significantly lower compared with the reported smoking exposure of the infant during the first year of follow-up (13$16 \% ; \mathrm{p}<0.001)$.

\begin{tabular}{|c|c|c|c|c|c|c|c|c|}
\hline \multirow{2}{*}{$\begin{array}{l}\text { TABLE } 2 \\
\text { Percentiles }\end{array}$} & \multicolumn{8}{|c|}{$\begin{array}{l}\text { Frequency distribution (percentiles) of } \\
\text { respiratory symptoms during the first year of } \\
\text { follow-up in } 836 \text { infants }\end{array}$} \\
\hline & & 0 & 10 & 25 & 50 & 75 & 90 & 100 \\
\hline \multicolumn{2}{|c|}{ Days with wheeze ${ }^{\#} \mathrm{n}$} & 0 & 0 & 0 & 5 & 18 & 52 & 344 \\
\hline \multicolumn{2}{|c|}{ Days with cough n } & 0 & 5 & 15 & 36 & 74 & 125 & 314 \\
\hline \multicolumn{2}{|c|}{$\begin{array}{l}\text { Days with exclusive } \\
\text { wheeze }^{\#} \text { (without } \\
\text { cough) } n\end{array}$} & 0 & 0 & 0 & 0 & 3 & 16 & 344 \\
\hline \multicolumn{2}{|c|}{$\begin{array}{l}\text { Days with exclusive cough } \\
\text { (without wheeze) } n\end{array}$} & 0 & 3 & 10 & 26 & 57 & 96 & 260 \\
\hline
\end{tabular}

\section{Infant lung function and respiratory outcome}

Of the 836 infants, $558(66.7 \%)$ infants wheezed for $\geqslant 1$ day and $801(95.8 \%)$ infants coughed for $\geqslant 1$ day during the first year of follow-up. Only 24 (2.9\%) parents out of 836 infants did not report any respiratory symptoms. Frequency distributions of numbers of days with wheeze, cough, exclusive wheeze and exclusive cough of all 836 infants with complete datasets during the first year of follow-up are shown in table 2.

Table 3 shows the relationship between the different lung function variables and number of days with respiratory symptoms using univariable Poisson regression analysis. Every $\mathrm{kPa} \cdot \mathrm{L}^{-1} \cdot \mathrm{s}^{-1}$ increase in Rrs was associated with a $12 \%$ increased risk for wheeze and 3\% increased risk for cough. Every second (s) increase in $\tau$ rs was associated with a 4.4 times higher risk for wheeze and 1.6 times higher risk for cough. Stronger associations were found between Rrs and $\tau$ rs and exclusive wheeze. Every $\mathrm{mL} \cdot \mathrm{kPa}^{-1}$ increase in $C_{\mathrm{rs}}$ was significantly associated with a $0.3 \%$ decreased risk for exclusive wheeze. No significant association was found between $C$ rs and wheeze (with or without cough) and/or (exclusive) cough. Adjusting for other possible risk factors for respiratory symptoms, including sex, gestational age, birthweight and length, siblings, birth season, maternal age, parental history of asthma or allergy , pre- and post-natal parental smoking, parental socioeconomic status, ethnicity, presence of pets during pregnancy, and breastfeeding and daycare attendance during the first year of follow-up, did not materially change the observed relationships (table 3). The only exception was the relationship between $C_{r s}$ and wheeze and (exclusive) cough. Every $\mathrm{mL} \cdot \mathrm{kPa}^{-1}$ increase in Crs was significantly associated with a $0.4 \%$ decreased risk for wheeze, $0.4 \%$ decreased risk for cough and $0.4 \%$ decreased risk for exclusive cough after adjusting for other possible risk factors for respiratory symptoms.

In order to further examine the effect of early life lung function and respiratory symptoms in the first year of follow-up, we studied the number of days with symptoms separated for the four quarters (fig. 2). The strongest effect of Rrs on the number of days with cough and wheeze was found in the first and last 3 months of the first year of follow-up. For $\mathrm{Crs}_{\mathrm{rs}}$ we found two different effects: higher values of $C_{\text {rs }}$ were associated with a significant increased risk for cough and wheeze in the first 6 months of follow-up and a significant decreased risk for 


\begin{tabular}{|c|c|c|c|c|}
\hline \multirow[b]{2}{*}{ Variable } & \multicolumn{2}{|c|}{ Univariable } & \multicolumn{2}{|c|}{ Multivariable $^{\#}$} \\
\hline & IRR (95\% CI) & p-value & IRR (95\% CI) & p-value \\
\hline \multicolumn{5}{|c|}{ Wheeze (with or without cough) } \\
\hline$\tau$ rs S & $4.38(3.90-4.91)$ & $<0.001$ & $4.59(3.96-5.31)$ & $<0.001$ \\
\hline \multicolumn{5}{|c|}{ Cough (with or without wheeze) } \\
\hline Crs $\mathrm{mL} \cdot \mathrm{kPa}^{-1}$ & $1.000(0.999-1.001)$ & 0.351 & $0.996(0.995-0.997)$ & $<0.001$ \\
\hline $\operatorname{Rrs~kPa} \cdot \mathrm{L}^{-1} \cdot \mathrm{s}^{-1}$ & $1.03(1.03-1.04)$ & $<0.001$ & $1.06(1.0-1.06)$ & $<0.001$ \\
\hline$\tau \mathrm{rs} \mathrm{S}$ & $1.55(1.44-1.67)$ & $<0.001$ & $1.72(1.56-1.89)$ & $<0.001$ \\
\hline \multicolumn{5}{|c|}{ Exclusive cough (without wheeze) } \\
\hline Crs $\mathrm{mL} \cdot \mathrm{kPa}^{-1}$ & $1.000(0.999-1.001)$ & 0.918 & $0.996(0.995-0.997)$ & $<0.001$ \\
\hline $\operatorname{Rrs~kPa} \cdot \mathrm{L}^{-1} \cdot \mathrm{s}^{-1}$ & $1.02(1.02-1.03)$ & $<0.001$ & $1.05(1.05-1.06)$ & $<0.001$ \\
\hline$\tau \mathrm{rS} \mathrm{S}$ & $1.35(1.24-1.47)$ & $<0.001$ & $1.64(1.47-1.83)$ & $<0.001$ \\
\hline
\end{tabular}

IRR: incidence risk ratio; Crs: compliance of the respiratory system; Rrs: resistance of the respiratory system; $\tau$ rs: time constant of the respiratory system. ${ }^{\#}$ : adjusted for sex, gestational age, birthweight and length, siblings, birth season, maternal age, parental history of asthma or allergy, parental smoking, parental socioeconomic status, ethnicity, presence of pets during pregnancy, and breastfeeding and daycare attendance during the first year of follow-up. ": multivariable Poisson regression models with exclusive wheeze and exclusive cough as outcome variables were adjusted for the above listed covariates and for exclusive cough and exclusive wheeze, respectively. Bold indicates significance.

cough and wheeze in the last 6 months of the first year of follow-up. $\tau$ rs is equal to the product of Rrs and $C r s$, which explains the high IRR in the first 3 months in life and the somewhat lower IRR after 3 months of follow-up.

\section{DISCUSSION}

This is the first prospective birth cohort study in healthy infants with daily parental outcome assessment providing data on the relationship between early life lung function and (exclusive) wheeze and (exclusive) cough as two separate entities during the first year of life. We have shown that $R$ rs, $C r s$ and $\tau$ rs were related to the number of days with (exclusive) cough and (exclusive) wheeze. Adjustments for other possible risk factors for respiratory symptoms early in life did not influence the observed relationships.

Some methodological aspects need to be considered. Respiratory symptoms were measured on a daily basis by parental report. This may lead to misclassification, as parents often confuse symptoms, especially of wheeze, with snoring or cough [20-22]. We tried to minimise this bias by carefully instructing parents how to recognise the various respiratory symptoms before they started completing in the questionnaires and parents were instructed to call the researchers if further explanation was required. Compared with other studies which prospectively assessed both wheeze and cough in unselected infants, frequency of respiratory symptoms was comparable, suggesting that misclassification is not a major issue in our study. In the study by LATZIN et al. [9], 92.8\% of the mothers reported $\geqslant 1$ week with cough or wheeze during the first year of life
(7.2\% of parents did not report any symptoms), which is comparable to the numbers of our study: $66.7 \%$ of infants wheezed $\geqslant 1$ day and $95.8 \%$ infants coughed $\geqslant 1$ day in the first year of follow-up, in $2.9 \%$ of infants no respiratory symptoms were reported during the first year of follow-up. DougLAS et al. [29] reported a long-tail distribution for number of days with cough and wheeze in the first year of life similar to our findings (unfortunately specific numbers are not provided in this article). Another disadvantage of self-administered daily diaries is a higher drop-out rate. Our sample included $70 \%$ of the eligible infants. Lung function measurement was unsuccessful in $20 \%$ of the infants. Of the included infants with available lung function data, $15 \%$ were lost to follow-up. This is higher than the $2.7 \%$ drop-out rate that LATZIN et al. [9] reported using weekly telephones interviews to assess respiratory symptoms. However, our drop-out rate was much lower than the $47 \%$ that DougLAS et al. [29] reported using self-administered daily diaries, probably due to our reinforcements by mail and telephone. The advantage of measuring respiratory symptoms on a daily basis by parental report is that very large numbers of infants can be studied, allowing analysis in subgroups. As characteristics of the infants with a follow-up of $\geqslant 9$ months did not differ from the group of infants with a follow-up of $>9$ months and no relevant differences were found between infants with and without successful lung function, it makes it unlikely that loss to follow-up substantially affected our results. Regarding the external validity of our findings some comments should be made on socioeconomic class. As reported by MOLENAAR et al. [30] in the study population of the Utrecht Health Project, almost 

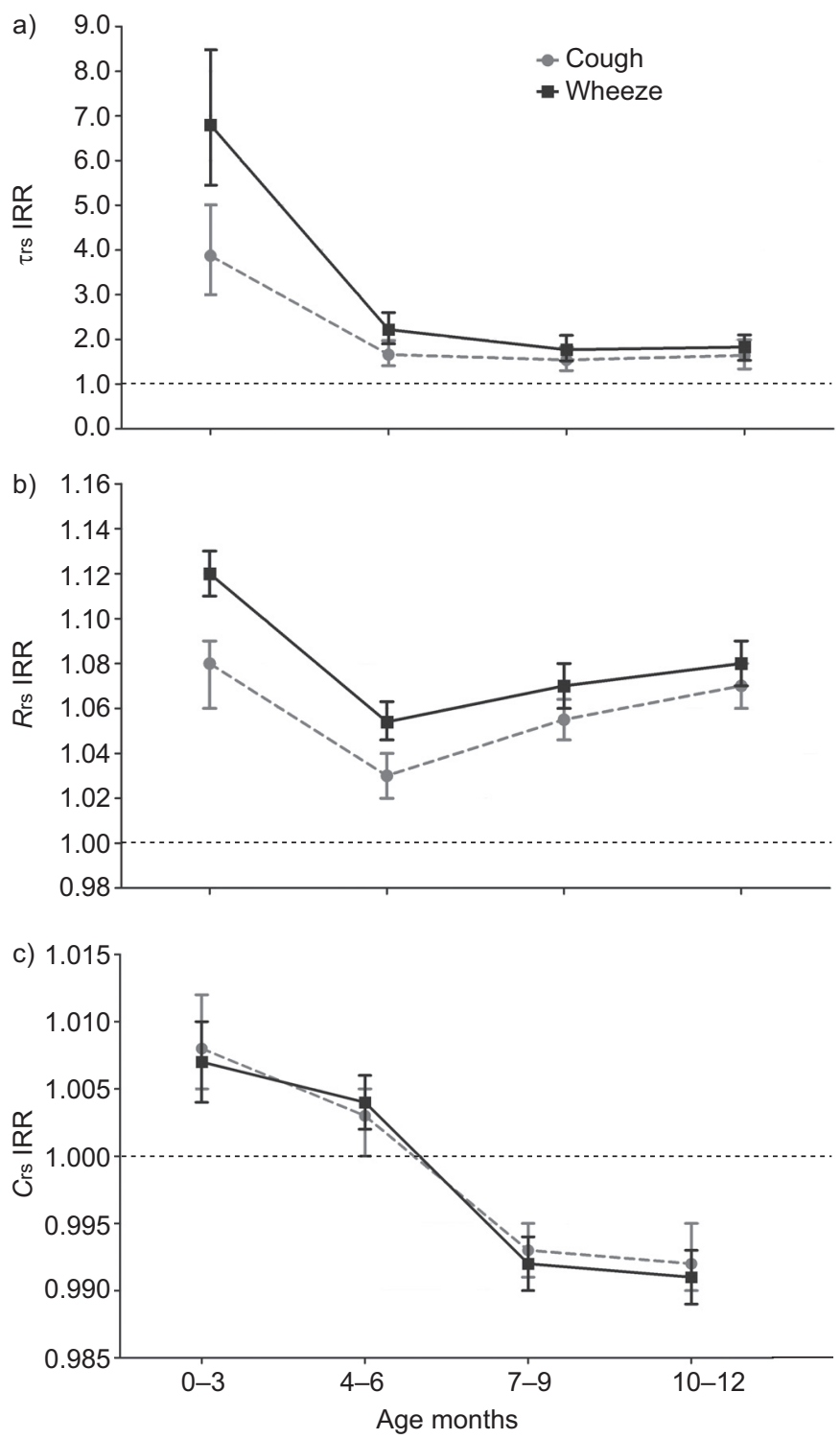

FIGURE 2. Adjusted incidence risk ratios (IRR) for days of respiratory symptoms during the first year of follow-up in relation to a) respiratory time constant ( $\tau r \mathrm{~s}), \mathrm{b})$ respiratory resistance (Rrs) and c) respiratory compliance (Crs). …..: IRR of 1.0 (nonincreased risk).

$40 \%$ of participants completed higher vocational or university education. Within the WHISTLER study this percentage was higher (around 60\%). It must be kept in mind that in this study we are dealing with young families whose socioeconomic status is by definition higher than the total population of the district (including people of all ages). Nevertheless, it could be that the participation rate is higher among parents with high socioeconomic status compared with parents with a low socioeconomic status resulting in a study population that is not entirely unselected. Although there is some selection, we consider selection bias unlikely. The latter would mean that parental reasons for nonparticipation were based on specific associations between lung function and respiratory symptoms that had not yet occurred. The findings from this study might, however, only be generalisable to middle and high socioeconomic class families with a relatively low percentage of children exposed to environmental tobacco smoke. Until similar studies have been performed in samples representing the general population, the degree to which these results are accurate for more broadly defined or special populations (e.g. low socioeconomic class families with high tobacco-smoke exposure) is uncertain.

Epidemiological research and public health practice concerning the development and prediction of childhood respiratory illnesses may benefit from lung function measurements early in life. Until relatively recently, longitudinal epidemiological studies of young infants involving assessment of lung function have been difficult to perform. The major limitation was the lack of simple, reliable and reproducible lung function tests that are applicable in a large open population of healthy infants. One of the new methods is the SOT, a noninvasive and easy applicable lung function technique for assessment of Rrs, Crs and $\tau$ rs [26]. Recently, we demonstrated that the feasibility and variability of lung function testing using the SOT is accurate for use in open populations of healthy neonates and infants [31]. In that study [31], we demonstrated that Rrs, Crs and $\tau$ rs measured using the SOT were independently related to wheeze and cough during the first year of follow-up. This is in contrast with Young et al. [10]. They assessed passive respiratory mechanics shortly after birth, but did not find any differences in $R$ rs or $C$ rs according to wheeze (never wheeze versus ever wheeze) throughout the first year of life. LODRUP CARLSEN et al. [15] also measured passive respiratory mechanics in 664 infants shortly after birth and found no significant influence of passive respiratory mechanics on the risk of developing recurrent or persistent bronchial obstruction.

It has been suggested that the risk of wheezing in infancy is increased by absolute smaller airway size, a reduction in elastic recoil pressure of the lung and a highly compliant chest wall [12]. The smaller airway calibre could be due to anatomical differences, subclinical inflammation or increased airway wall compliance. Viral infections or asthmatic inflammation can induce additional narrowing of the peripheral airways and might easily result in wheezing in children with pre-existing reduced airway calibre, as reflected by early life lung function $[12,32]$. Our data support the hypothesis that a significant portion of the number of days with wheeze experienced in the first year of life is most likely to be triggered by reduced airway calibre (increased Rrs) early in life. For number of days with cough a similar significant association was found, although somewhat weaker compared with wheeze. This was also found in a study in older children at the age of $3 \mathrm{yrs}$, where airway resistance was not only related to wheeze but also independently related to cough [33]. The relationship between resistance and subsequent coughing and wheezing was most evident in the first and last 3 months of the first year of follow-up. Regarding respiratory compliance, higher values of $C_{r s}$ were associated with a significant increased risk for cough and wheeze in the first 6 months of follow-up and significant decreased risk for cough and wheeze after 6 months of followup. This may suggest that early cough and wheeze in the first year of life have different aetiologies compared with wheeze and cough later in the first year of life due to innate morphological lung characteristics that change over time. $\tau_{\mathrm{rs}}$ is equal to the product of $R$ rs and $C r s$, which explains the high IRR in the first 3 months in follow-up (higher values of Rrs and Crs 
related to an increased risk for cough and wheeze) and the somewhat lower IRR after 3 months of follow-up (higher values of $R$ rs and lower values of $C$ rs related to an increased risk for cough and wheeze).

CHAWES et al. [34] described an elevated fraction of exhaled nitric oxide in asymptomatic neonates born to asthmatic mothers preceding the development of transient early wheezing, but not persistent wheezing. These findings are in line with earlier findings of LATZIN et al. [35]. CHAWES et al. [34] propose that in addition to small airway calibre, an early nitric oxide-related disease process contributes to the transient wheezing phenotype. They argue that this finding may be a clue for new therapeutic strategies. However, like our current findings, most studies suggest a small airway calibre as the most important cause of transient wheezing in young children [10], and other studies fail to show that inflammatory components are related [36].

We found that the associations between passive respiratory mechanics measured shortly after birth and cough and wheeze during the first year of follow-up remained significant after adjusting for other possible risk factors, including sex, gestational age, birthweight and length, siblings, birth season, maternal age, parental history of asthma or allergy, parental smoking, parental socioeconomic status, ethnicity, presence of pets during pregnancy, and breastfeeding and daycare attendance during the first year of follow-up. This obviously does not mean that these major covariates do not increase the risk of cough and wheeze. However, it indicates that other hereditary or environmental factors influence lung growth and development during pregnancy and early in life, independent of these major covariates. Regarding post-natal smoking exposure of the infant, the reported smoking exposure between birth and before inclusion in the study at $<2$ months of age was significantly lower compared with the reported smoking exposure of the infant during the first year of follow-up, suggesting that some parents may have under-reported smoking at the time of inclusion. Possible explanations for this difference include: 1) most smoking parents mentioned that since the birth of the infant they still actively smoked, albeit outside the house (smoke exposure of the infant was scored negative at the time of inclusion in the study) and possibly returned to "their bad habit" of smoking in the primary residency in the presence of the infant during the first year of follow-up; and 2) some parents may have under-reported smoking at the time of inclusion because of the known adverse effects to the infant.

For clinical and, consequently, for research purposes it is important to clearly define different phenotypes of respiratory illnesses in young children, because the causes and the consequences may be different. Until now, epidemiological and aetiological studies described symptom complexes such as "recurrent wheeze and cough", "viral wheeze" or "asthmatic bronchitis". These phenotypes are focused on the time course of disease (transient, persistent or late onset wheeze) or on its aetiology (transient, nonatopic or immunoglobulin E-mediated wheeze) [37]. This study demonstrated that both cough and wheeze were associated with reduction of effective airway calibre. Additionally, a more compliant lung was associated with an increased risk for cough and wheeze in the first 6 months of follow-up and decreased risk after 6 months of follow-up. As the strength of the relationships was different for cough and wheeze, it is important to use cough and wheeze as two separate entities for clinical and research purposes.

In conclusion, this large birth cohort study in healthy infants with daily parental outcome assessment provided data on the relationship between early life lung function and wheeze and cough as two separate entities during the first year of life. Rrs, $C_{\text {rs }}$ and $\tau$ rs measured shortly after birth were independently associated with cough and wheeze during the first year of life. As the strength of the relationhips are different for cough and wheeze it is important to use cough and wheeze as two separate entities. Further confirmation of these findings may lead to different approaches towards diagnosis, prevention and treatment of respiratory symptoms early in life.

\section{SUPPORT STATEMENT}

This study was funded by the Health Research and Development Council of the Netherlands (grant number 2001-1-1322) and by an unrestricted grant from Glaxo-Smith-Kline Netherlands. Neither of these funding sources had any role or influence on the study execution. The Utrecht Health Project was funded by the University of Utrecht, the University Medical Centre Utrecht, the Governmental Ministry of Health, the Health Research and Development Council of the Netherlands, the College of Health Insurance Companies and the Foundation of Former National Health Insurers.

\section{STATEMENT OF INTEREST}

A statement of interest for the study itself can be found at www.erj. ersjournals.com/site/misc/statements.xhtml

\section{REFERENCES}

1 Kuehni CE, Davis A, Brooke AM, et al. Are all wheezing disorders in very young (preschool) children increasing in prevalence? Lancet 2001; 357: 1821-1825.

2 Koopman LP, Brunekreef B, de Jongste JC, et al. Definition of respiratory symptoms and disease in early childhood in large prospective birth cohort studies that predict the development of asthma. Pediatr Allergy Immunol 2001; 12: 118-124.

3 Sears MR. Epidemiology of childhood asthma. Lancet 1997; 350: 1015-1020.

4 Stevens CA, Turner D, Kuehni CE, et al. The economic impact of preschool asthma and wheeze. Eur Respir J 2003; 21: 1000-1006.

5 Taussig LM, Wright AL, Morgan WJ, et al. The Tucson Children's Respiratory Study. I. Design and implementation of a prospective study of acute and chronic respiratory illness in children. Am J Epidemiol 1989; 129: 1219-1231.

6 Sherriff A, Peters TJ, Henderson J, et al. Risk factor associations with wheezing patterns in children followed longitudinally from birth to 3(1/2) years. Int J Epidemiol 2001; 30: 1473-1484.

7 Koopman LP, Smit HA, Heijnen ML, et al. Respiratory infections in infants: interaction of parental allergy, child care, and siblings the PIAMA study. Pediatrics 2001; 108: 943-948.

8 Gold DR, Burge HA, Carey V, et al. Predictors of repeated wheeze in the first year of life: the relative roles of cockroach, birth weight, acute lower respiratory illness, and maternal smoking. Am J Respir Crit Care Med 1999; 160: 227-236.

9 Latzin P, Frey U, Roiha HL, et al. Prospectively assessed incidence, severity, and determinants of respiratory symptoms in the first year of life. Pediatr Pulmonol 2007; 42: 41-50.

10 Young S, Arnott J, O'Keeffe PT, et al. The association between early life lung function and wheezing during the first 2 yrs of life. Eur Respir J 2000; 15: 151-157. 
11 Yuksel B, Greenough A, Giffin F, et al. Tidal breathing parameters in the first week of life and subsequent cough and wheeze. Thorax 1996; 51: 815-818.

12 Martinez FD, Morgan WJ, Wright AL, et al. Diminished lung function as a predisposing factor for wheezing respiratory illness in infants. N Engl J Med 1988; 319: 1112-1117.

13 Tager IB, Hanrahan JP, Tosteson TD, et al. Lung function, pre- and post-natal smoke exposure, and wheezing in the first year of life. Am Rev Respir Dis 1993; 147: 811-817.

14 Clarke JR, Salmon B, Silverman M. Bronchial responsiveness in the neonatal period as a risk factor for wheezing in infancy. Am J Respir Crit Care Med 1995; 151: 1434-1440.

15 Lodrup Carlsen KC, Carlsen KH, Nafstad P, et al. Perinatal risk factors for recurrent wheeze in early life. Pediatr Allergy Immunol 1999; 10: 89-95.

16 Wright AL, Holberg CJ, Morgan WJ, et al. Recurrent cough in childhood and its relation to asthma. Am J Respir Crit Care Med 1996; 153: 1259-1265.

17 Clough JB, Williams JD, Holgate ST. Effect of atopy on the natural history of symptoms, peak expiratory flow, and bronchial responsiveness in 7- and 8-year-old children with cough and wheeze. A 12-month longitudinal study. Am Rev Respir Dis 1991; 143: 755-760.

18 Brooke AM, Lambert PC, Burton PR, et al. The natural history of respiratory symptoms in preschool children. Am J Respir Crit Care Med 1995; 152: 1872-1878.

19 McKenzie S. Cough - but is it asthma? Arch Dis Child 1994; 70: 1-2.

20 Elphick HE, Sherlock P, Foxall G, et al. Survey of respiratory sounds in infants. Arch Dis Child 2001; 84: 35-39.

21 Lowe L, Murray CS, Martin L, et al. Reported versus confirmed wheeze and lung function in early life. Arch Dis Child 2004; 89: 540-543.

22 Cane RS, Ranganathan SC, McKenzie SA. What do parents of wheezy children understand by "wheeze"? Arch Dis Child 2000; 82: 327-332.

23 Bont L, Steijn M, van Aalderen WM, et al. Seasonality of long term wheezing following respiratory syncytial virus lower respiratory tract infection. Thorax 2004; 59: 512-516.

24 Katier N, Uiterwaal CSPM, de Jong BM, et al. The Wheezing Illnesses Study Leidsche Rijn (WHISTLER): Rationale and design. Eur J Epidemiol 2004; 19: 895-903.
25 Mortola JP, Saetta M. Measurements of respiratory mechanics in the newborn: a simple approach. Pediatr Pulmonol 1987; 3: 123-130.

26 Fletcher ME, Baraldi B, Steinbrugger B. Passive respiratory mechanics. In: Stock J, Sly PD, Tepper RS, et al. eds. Infant Respiratory Function Testing. New York, Wiley-Liss, 1996; pp. 283-327.

27 Gappa M, Colin AA, Goetz I, et al. Passive respiratory mechanics: the occlusion techniques. Eur Respir J 2001; 17: 141-148.

28 Grobbee DE, Hoes AW, Verheij TJ, et al. The Utrecht Health Project: optimization of routine healthcare data for research. Eur I Epidemiol 2005; 20: 285-287.

29 Douglas RM, Woodward A, Miles H, et al. A prospective study of proneness to acute respiratory illness in the first two years of life. Int J Epidemiol 1994; 23: 818-826.

30 Molenaar EA, van Ameijden EJ, Vergouwe Y, et al. Effect of nutritional counselling and nutritional plus exercise counselling in overweight adults: a randomized trial in multidisciplinary primary care practice. Fam Pract 2010; 27: 143-150.

31 Katier N, Uiterwaal CS, de Jong BM, et al. Feasibility and variability of neonatal and infant lung function measurement using the single occlusion technique. Chest 2005; 128: 1822-1829.

32 Martinez FD, Morgan WJ, Wright AL, et al. Initial airway function is a risk factor for recurrent wheezing respiratory illnesses during the first three years of life. Group Health Medical Associates. Am Rev Respir Dis 1991; 143: 312-316.

33 Smith JA, Drake R, Simpson A, et al. Dimensions of respiratory symptoms in preschool children: population-based birth cohort study. Am J Respir Crit Care Med 2008; 177: 1358-1363.

34 Chawes BL, Buchvald F, Bischoff AL, et al. Elevated exhaled nitric oxide in high-risk neonates precedes transient early but not persistent wheeze. Am J Respir Crit Care Med 2010; 182: 138-142.

35 Latzin P, Kuehni CE, Baldwin DN, et al. Elevated exhaled nitric oxide in newborns of atopic mothers precedes respiratory symptoms. Am J Respir Crit Care Med 2006; 174: 1292-1298.

36 Saglani S, Malmstrom K, Pelkonen AS, et al. Airway remodeling and inflammation in symptomatic infants with reversible airflow obstruction. Am J Respir Crit Care Med 2005; 171: 722-727.

37 Kuehni CE. Phenotype specific treatment of obstructive airways disease in infancy and childhood: new recommendations of the Swiss Paediatric Pulmonology Group. Swiss Med Wkly 2005; 135: 95-100. 